\title{
Matrix Converter Open Circuit Behavior Analysis
}

\author{
Jiawei Zhang, Christopher Brunson, James Bowden, Patrick Wheeler, Liliana De Lillo \\ The University of Nottingham \\ United Kingdom \\ eexjz28@nottingham.ac.uk
}

\begin{abstract}
The matrix converter current recirculating path during an open circuit condition is given in detail with the aim of contributing more expert knowledge to a fault detection system for matrix converter. Simulation results were obtained demonstrating how current recirculates in the matrix converter and the clamp circuit during an open-circuit fault. Healthy output phase currents can be canceled to zero due to current recirculating via the clamp circuit. This result could contribute expert knowledge to a fault detection system to avoid false fault detection and diagnosis.
\end{abstract}

Index Terms-Matrix Converter, Open Circuit, Clamp Circuit, Current Recirculation.

\section{INTRODUCTION}

Matrix converters posses advantages such as compact power circuit topology, the possibility of higher power density [1], controllable input power factor [2], [3], and removal of DCLink capacitor [4]. Therefore, research attention has focused on the matrix converter topology for many applications in safety critical systems such as aerospace. Modulation methods and current commutation techniques of AC-AC matrix converters have been developed in literature [1] [5] [6]. Comparisons of the reliability between the matrix converter and other ACAC converter topologies are presented in the literature [7] [8].

It is inevitable that a fault will occur during the systems lifetime. In order for continued operation, fault detection and diagnosis for the matrix converter must be both fast and reliable to minimize the hazard of over-voltage or over-current condition. There are many different types of faults which could occur in matrix converters, such as IGBT failure, diode failure, gate drive failure, and controller communication failure [9]. This paper focuses on open-circuit switch faults. Before doing fault detection and diagnosis, it is important to know how currents will recirculate in the clamp circuit during an open circuit fault condition. Simple AC-AC topologies such as 6pulse diode rectifier and PWM inverter current recirculating behavior has been well understood in literature [10] [11]. Since matrix converters have many switches and a diode clamp circuit is implemented for protection purpose, the current recirculating paths during an open circuit fault condition are not well understood in other literature. In literature [9] [12] [13] , the clamp circuit capacitor current knowledge is used for fault detection and diagnosis. An open circuit fault can be detected when the clamp circuit capacitor current is measured as a non-zero value. Another literature [14] proposes three

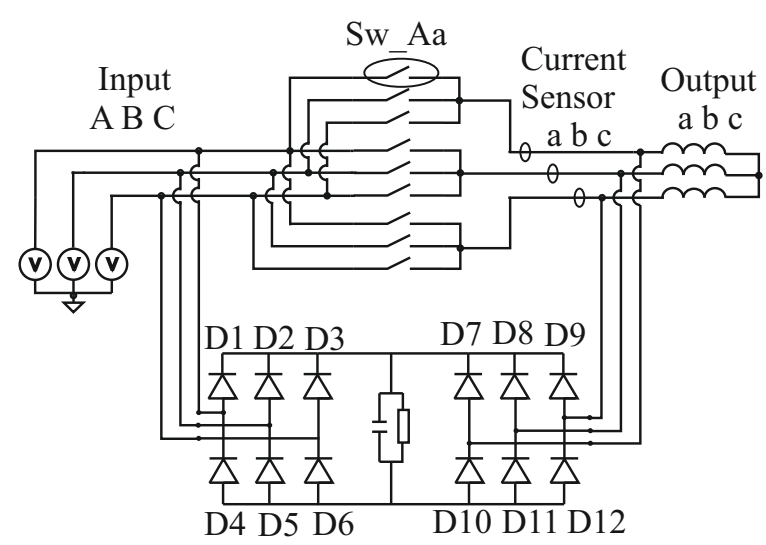

Fig. 1: Circuit Diagram of the Matrix Converter with the Clamp Circuit

possible current recirculating paths when an open circuit fault occurs. However, neither simulation result nor experimental result is provided to validate the idea.

This paper presents the matrix converter current recirculating behavior during an open circuit fault condition when a clamp circuit is implemented. The proposed idea is validated using SYNOPSYS SABER simulation tool.

\section{Matrix CONVERTER Operation During AN Open Circuit SWITCH FAUlT}

Matrix converters provided no free-wheeling mechanism, so a clamp circuit is needed to protect it from over-voltage during open-circuit fault conditions as shown in Fig 1. Normally, the matrix converter input terminals should not be short circuited because it is fed by a voltage source. On the other hand, an output phase of a matrix converter must never be open circuited due to inductive load nature [1]. Hence, the switching duty cycle of the matrix converter must satisfy the condition expressed in equation 1 .

$$
\begin{array}{r}
0 \leq m_{h k} \leq 1, \quad h=A, B, C, k=a, b, c . \\
m_{A a}+m_{B a}+m_{C a}=1 \\
m_{A b}+m_{B b}+m_{C b}=1 \\
m_{A c}+m_{B c}+m_{C c}=1
\end{array}
$$


TABLE I: Valid SVM switching configurations for matrix converters [6]

\begin{tabular}{|c|c|}
\hline $\begin{array}{l}\text { Switching } \\
\text { configuration }\end{array}$ & $\begin{array}{l}\text { Switches } \\
\text { On }\end{array}$ \\
\hline+1 & $S_{A a} S_{B b} S_{B c}$ \\
\hline-1 & $S_{B a} S_{A b} S_{A c}$ \\
\hline+2 & $S_{B a} S_{C b} S_{C c}$ \\
\hline-2 & $S_{C a} S_{B b} S_{B c}$ \\
\hline+3 & $S_{C a} S_{A b} S_{A c}$ \\
\hline-3 & $S_{A a} S_{C b} S_{C c}$ \\
\hline+4 & $S_{B a} S_{A b} S_{B c}$ \\
\hline-4 & $S_{A a} S_{B b} S_{A c}$ \\
\hline+5 & $S_{C a} S_{B b} S_{C c}$ \\
\hline-5 & $S_{B a} S_{C b} S_{B c}$ \\
\hline+6 & $S_{A a} S_{C b} S_{A c}$ \\
\hline-6 & $S_{C a} S_{A b} S_{C c}$ \\
\hline+7 & $S_{B a} S_{B b} S_{A c}$ \\
\hline-7 & $S_{A a} S_{A b} S_{B c}$ \\
\hline+8 & $S_{C a} S_{C b} S_{B c}$ \\
\hline-8 & $S_{B a} S_{B b} S_{C c}$ \\
\hline+9 & $S_{A a} S_{A b} S_{C c}$ \\
\hline-9 & $S_{C a} S_{C b} S_{A c}$ \\
\hline $0_{A}$ & $S_{A a} S_{A b} S_{A c}$ \\
\hline $0_{B}$ & $S_{B a} S_{B b} S_{B c}$ \\
\hline $0_{C}$ & $S_{C a} S_{C b} S_{C c}$ \\
\hline
\end{tabular}

Variables $m_{h k}$ are the duty cycles of nine bidirectional switches $S w_{h k}$ in the matrix converter. The variable $h$ represents the input side and $k$ represents the output side. Space Vector Modulation $(S V M)$ method is used in this paper.The 18 active vectors and 3 zero vectors are presented in TABLE I. In $S V M$, the choice of which active vectors to apply is dependent on the input-output sector combinations as shown in TABLE II [6].

In order to demonstrate clearly how the outputs connect to the inputs during any input-ouput sector combination, TABLE III is presented to show which input phase is connected to the output phase $a$ at any sector combination.

Output current sensors required for control purposes are usually placed after the clamp circuit. However, in this paper, the current sensors are connected in-between the switch matrix and the RL-load, ahead of the clamp circuit connection in order to implement fault detection technique [14]. When a switch open-circuit fault occurs, the current recirculating path can be classified into two types. For a type 1 open-circuit as shown in Fig 2, load currents recirculate only through the output side of the clamp circuit and back to the load side. In type 1 , output current sensors could not detect any current flowing through the matrix converter. During a type 2 opencircuit as shown in Fig 3, load currents recirculate through the input and output side of the clamp circuit, the matrix converter and back to the load side. For a type 2 recirculating path, output current sensors could detect the current flowing through the matrix converter. Taking sector combination of Input $_{5}$ and Output $_{2}$ for instance, Type 1 and type 2 current recirculating paths are shown in Figure 2 and Figure 3. These two current recirculating paths are drawn during zero and active vector period respectively, since the output matrix converter current will be measured within the zero vectors [14] or within the active vectors for fault detection purpose.

Recirculating currents in the matrix converter, load and



Fig. 2: Type 1 open-circuit current recirculating path

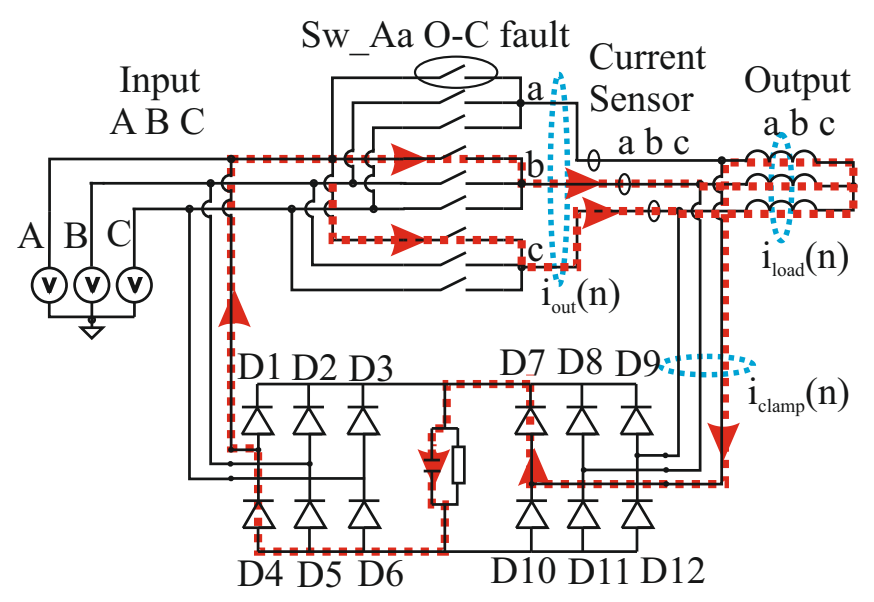

Fig. 3: Type 2 open-circuit current recirculating path

clamp circuit satisfy the Kirchhoff Current Law (KCL) as shown in equation 2 . Where $i_{\text {load }}(n), i_{\text {out }}(n)$ and $i_{\text {clamp }}(n)$ are three phase load currents, matrix converter output currents, and clamp circuit output side currents respectively as shown in Fig 2 and 3.

$$
\begin{aligned}
\sum_{n=1}^{3} i_{\text {load }}(n)= & \sum_{n=1}^{3}\left(i_{\text {out }}(n)+i_{\text {clamp }}(n)\right)=0 \\
& \sum_{n=1}^{3} i_{\text {out }}(n)=-\sum_{n=1}^{3} i_{\text {clamp }}(n)
\end{aligned}
$$

Three output current sensors are placed in-between the switch matrix and the RL-load, ahead of the clamp circuit connection as shown in Fig 1. These three output current sensors will directly measure the matrix converter output current rather than load current. The output current will be sampled within the three zero vectors. A symmetrical switching pattern utilizing four active vectors and three different zero vectors is 
TABLE II: Switching configuration for each input-ouput sector combination [6]

\begin{tabular}{|c|c|c|c|c|c|c|c|c|c|c|c|c|c|c|c|c|c|c|}
\hline & \multicolumn{3}{|c|}{ Output $_{1}$} & \multicolumn{3}{|c|}{$\overline{\text { Output }_{2}}$} & \multicolumn{3}{|c|}{ Output $_{3}$} & \multicolumn{3}{|c|}{ Output $_{4}$} & \multicolumn{3}{|c|}{ Output $_{5}$} & \multicolumn{3}{|c|}{ Output $_{6}$} \\
\hline Input $_{1}$ & $-9+7$ & +3 & -1 & $+6-4$ & -9 & +7 & $-3+1$ & +6 & -4 & $+9-7$ & -3 & +1 & $-6+4$ & +9 & -7 & $+3-1$ & -6 & +4 \\
\hline Input $_{2}$ & $+8-9$ & -2 & +3 & $-5+6$ & +8 & -9 & $+2-3$ & -5 & +6 & $-8+9$ & +2 & -3 & $+5-6$ & -8 & +9 & $-2+3$ & +5 & -6 \\
\hline Input $_{3}$ & $-7+8$ & +1 & -2 & $+4-5$ & -7 & +8 & $-1+2$ & +4 & -5 & $+7-8$ & -1 & +2 & $-4+5$ & +7 & -8 & $+1-2$ & -4 & +5 \\
\hline Input $_{4}$ & $+9-7$ & -3 & +1 & $-6+4$ & +9 & -7 & $+3-1$ & -6 & +4 & $-9+7$ & +3 & -1 & $+6-4$ & -9 & + & $-3+1$ & +6 & -4 \\
\hline Input $_{5}$ & $-8+9$ & +2 & -3 & $+5-6$ & -8 & +9 & $-2+3$ & +5 & -6 & $+8-9$ & -2 & +3 & $-5+6$ & +8 & -9 & $+2-3$ & -5 & +6 \\
\hline Input $_{6}$ & $+7-8$ & -1 & +2 & $-4+5$ & +7 & -8 & $+1-2$ & -4 & +5 & $-7+8$ & +1 & -2 & $+4-5$ & -7 & +8 & $-1+2$ & +4 & -5 \\
\hline
\end{tabular}

TABLE III: Switch state table for output phase $a$

\begin{tabular}{|c|c|c|c|c|c|c|}
\hline Phase $_{a}$ & Output $_{1}$ & Output $_{2}$ & Output $_{3}$ & Output $_{4}$ & Output $_{5}$ & Output $_{6}$ \\
\hline Input $_{1}$ & $C B C B$ & $A A C B$ & $A A A A$ & $A A A A$ & $C B A A$ & $C B C B$ \\
\hline Input $_{2}$ & $C C C C$ & $B A C C$ & $B A B A$ & $B A B A$ & $C C B A$ & $C C C C$ \\
\hline Input $_{3}$ & $A C A C$ & $B B A C$ & $B B \quad B \quad B$ & $B B \quad B \quad B$ & $A C B \quad B$ & $A C A C$ \\
\hline Input $_{4}$ & $A A A A$ & $C B A A$ & $C B C B$ & $C B C B$ & $A A C B$ & $A A A A$ \\
\hline Input $_{5}$ & $B A B A$ & $C C A \quad B \quad A$ & $C C C C$ & $C C C C$ & $B A C C$ & $B A B A$ \\
\hline Input $_{6}$ & $B \quad B \quad B \quad B$ & $A C B \quad B$ & $A C A C$ & $A C A C$ & $B B A C$ & $B \quad B \quad B \quad B$ \\
\hline
\end{tabular}

applied to the space vector modulation. The current sampling point for fault detection purpose is presented in Fig 4.

When bidirectional switch $S w_{A a}$ occurs as shown in Fig 2 and Fig 3, output current sensor a could detection the zero current during zero vector $0_{A}\left(S w_{A a} S w_{A b} S w_{A c}\right)$. However, output phase $b$ and $c$ current will be influenced by the output phase $a$ current, and could be canceled to zero at some sector combinations. These sector combinations are Input $_{1}$

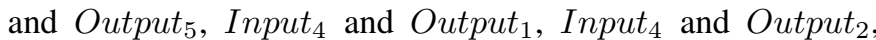
Input $_{5}$ and Output $_{1}$, Input $_{5}$ and Output $_{2}$. In these five sector combinations, type 1 recirculating path presented in Fig 2 will occur during the output currents sampling period.

Taking sector combination Input $_{5}$ and Output $t_{2}$ for instance, output phase $b$ and $c$ are connected to the input phase $A$ in zero vector $0_{A}$. Since clamp circuit diode $D 7$ conducts ( Iout $_{a} \leq 0$ ), the current recirculating path conducts through the diode connecting to the most negative voltage. In addition, considering the current direction of Iout $_{b}$ and Iout , $_{c}$, the output phase voltages Vout $_{b}$ and Vout $_{c}$ are more negative than $\operatorname{Vin}_{A}$ due to the voltage drop of the bidirectional switch during the zero vector $0_{A}$ period. Therefore, only the output side of the clamp circuit will recirculate during zero vector $0_{A}$ as shown in Figure 2. Since no current will recirculate to the input side clamp circuit and back to the output current sensors, current sensors $b$ and $c$ will detect zero current and a false diagnosis will occur. This false diagnosis indicates that $S w_{A b}$ and $S w_{A c}$ are open-circuit faults. However, They are both healthy.

In order to avoid a false diagnosis mentioned above, more expert knowledge is required such as input voltage amplitude and direction, output current amplitude and direction, and nine bidirectional switching states information to contribute to a fault detection technique.

\section{Simulation Details}

A simulation of a matrix converter with close loop current operation system has been created using SYNOPSYS SABER. The block diagram of the matrix converter system is presented in Fig 5. The converter is switched with the SVM method and

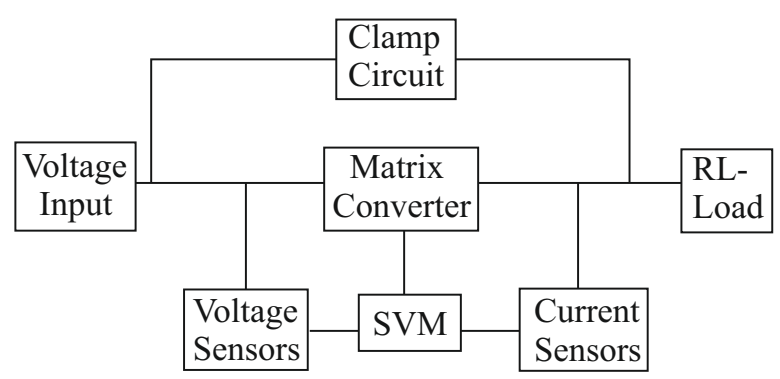

Fig. 5: Block diagram of the matrix converter simulation model

the output current is regulated by a PI compensated control loop.

\section{A. Parameters of the simulation}

Three phase input voltages and frequency are set to be $60 \mathrm{~V}$ and $50 \mathrm{~Hz}$ respectively. The reference balanced three phase output currents are set to be $10 \mathrm{~A} \mathrm{rms}$, with the output frequency set to $180 \mathrm{~Hz}$. In addition, the SVM switching sequence is $0_{C}->V_{1}->V_{3}->0_{A}->V_{4}->V_{2}->$ $0_{B}->0_{B}->V_{2}->V_{4}->0_{A}->V_{3}->V_{1}->0_{C}$ as shown in Fig 4. Where $V_{1}, V_{2}, V_{3}, V_{4}$ are the four active vectors as presented in Table II.

\section{RESUlts AND ANALYSiS}

Simulation results are obtained for all 36 input-output sector combinations when an open circuit bidirectional switch $S w_{A a}$ fault condition occurs. Specifically, current sensor $b$ and $c$ will detect the zero current within zero vector $0_{A}$ period among all the possible 5 sector combinations of Input $_{1}$ and Output $_{5}$, Input $_{4}$ and Output $_{1}$, Input 4 and Output In $_{4}$, Input $t_{5}$ and Output $_{1}$, Input $_{5}$ and Output I $_{2}$. Simulation results of sector

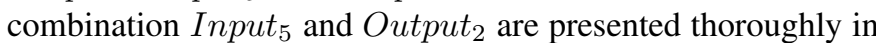
Fig 6 to 8 . Normal and open circuit operation output current waveforms are shown in Fig 6 (a) and (b) respectively.

Clamp circuit diodes current waveforms during an open circuit fault condition are presented in Fig 7, where it can 


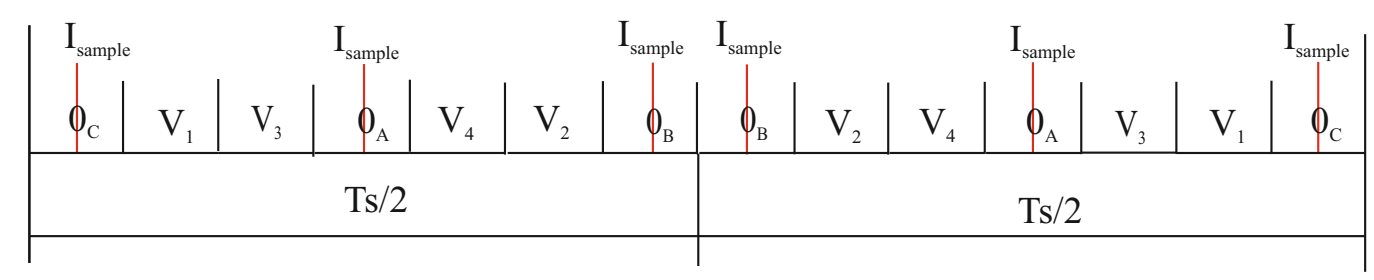

Fig. 4: Current sampling points for fault detection purpose

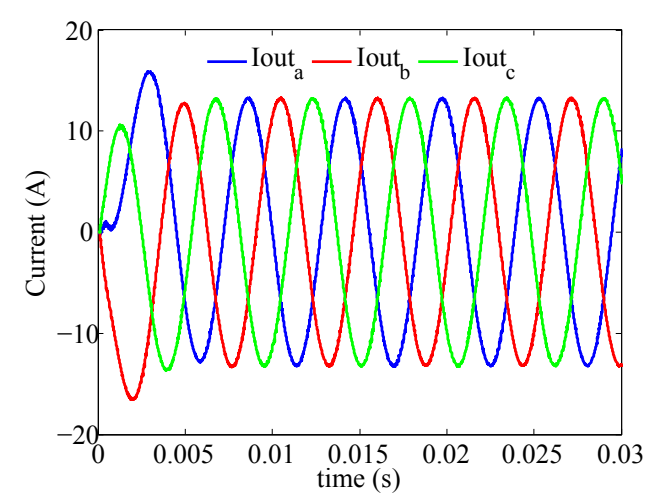

(a) Normal operation

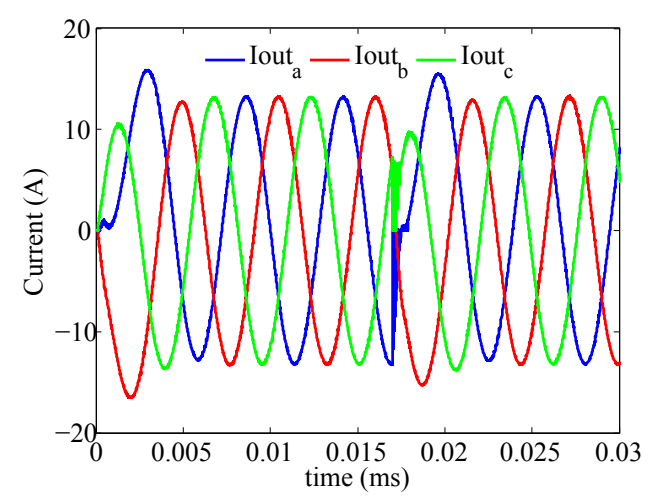

(b) Open circuit fault operation

Fig. 6: Matrix converter output current under normal and open circuit fault operation

be seen that clamp circuit diodes $D 4, D 7, D 11, D 12$ are conducting. Both type 1 path shown in Fig 2 and type 2 path shown in Fig 3 occur in the simulation.

When magnifying the clamp circuit diodes current waveforms presented in Fig 8, it can be seen that clamp circuit diode $D 4$ is not conducting within the zero vector $0_{A}$ period under an open circuit fault condition. Therefore, only type 1 current recirculating path, as shown in Fig 2, is occurring and output phase $b$ and $c$ currents are canceled to zero as shown in Fig 8e.

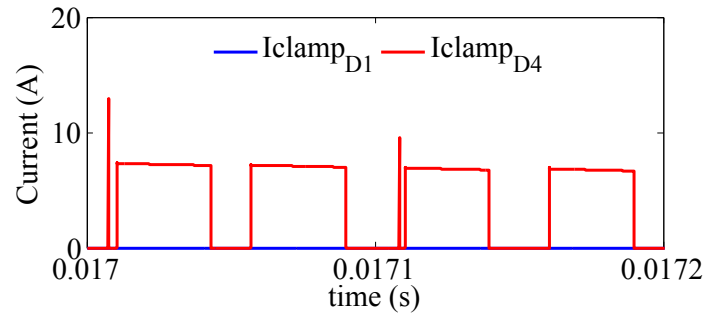

(a) Clamp circuit diode $D 1$ and $D 4$ current under open circuit

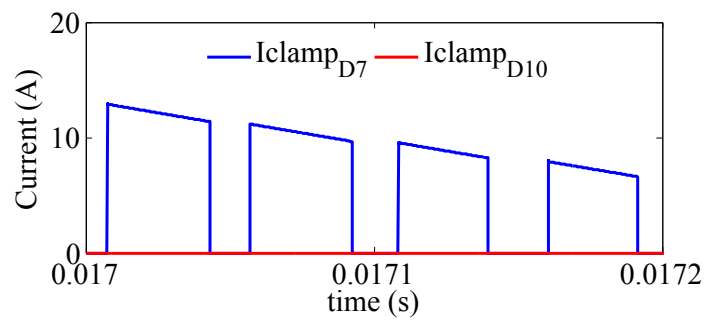

(b) Clamp circuit diode D7 and D10 current under open circuit

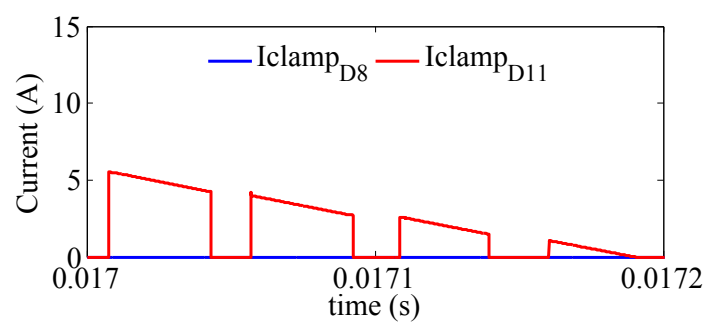

(c) Clamp circuit diode $D 8$ and $D 11$ current under open circuit

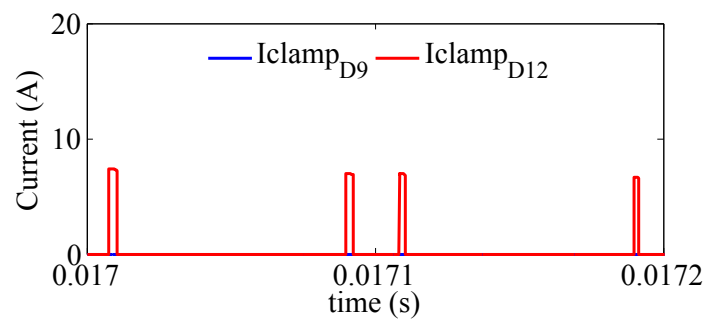

(d) Clamp circuit diode $D 9$ and $D 12$ current under open circuit

Fig. 7: Clamp circuit diode currents under an open circuit fault condition 


\section{CONCLUSION}

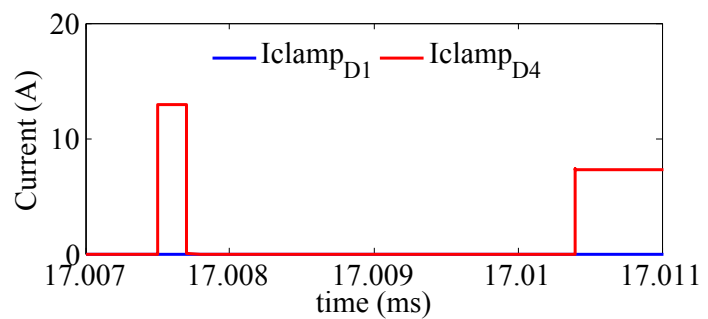

(a) Clamp circuit diode $D 1$ and $D 4$ current under open circuit

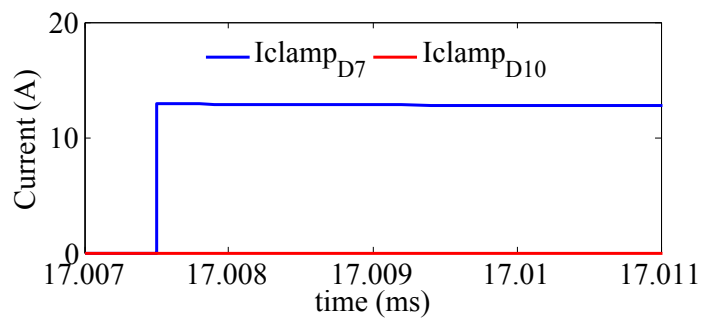

(b) Clamp circuit diode D7 and D10 current under open circuit



(c) Clamp circuit diode $D 8$ and $D 11$ current under open circuit

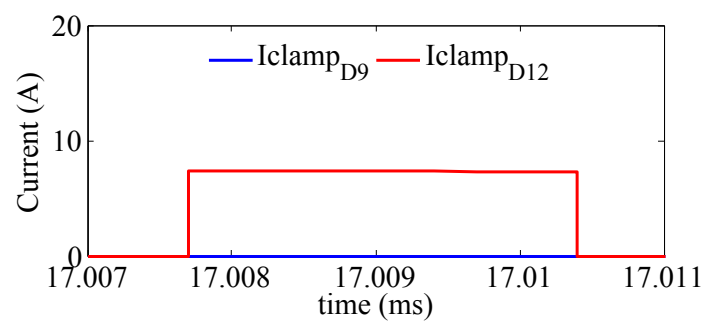

(d) Clamp circuit diode $D 9$ and $D 12$ current under open circuit

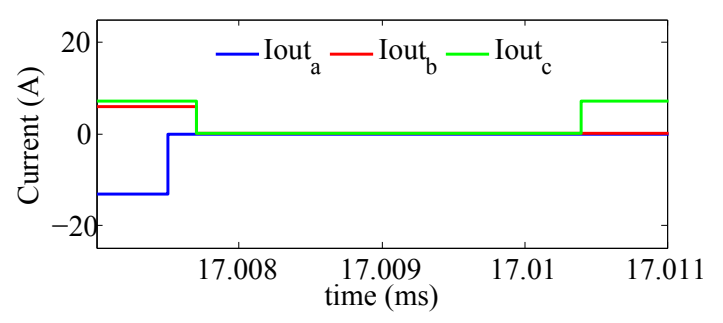

(e) Magnified matrix converter output currents

Fig. 8: Magnified open circuit clamp circuit diode currents and output currents within zero vector $0_{A}$ period
This paper has presented a complete recirculating path analysis for matrix converters under an open circuit fault condition. When the current recirculating through the outputside clamp circuit and back to the load, there will be no current measured in the output current sensor, which could cause healthy output phases to be falsely diagnosed as open circuit. If the current recirculates through the matrix converter and back to the load, the output current can be detected in the output current sensor, which could avoid false diagnosis. This current recirculating rule is extremely valuable and can contribute to a fault detection and diagnosis system to improve the precision of the fault detection and diagnosis method in matrix converters.

\section{REFERENCES}

[1] P. W. Wheeler, J. Rodriguez, J. C. Clare, L. Empringham, and A. Weinstein, "Matrix converters: a technology review," Industrial Electronics, IEEE Transactions on, vol. 49, no. 2, pp. 276-288, 2002.

[2] B. Metidji, N. Taib, L. Baghli, T. Rekioua, and S. Bacha, "Novel single current sensor topology for venturini controlled direct matrix converters," Power Electronics, IEEE Transactions on, vol. 28, no. 7, pp. 3509-3516, 2013.

[3] S. Ishikawa and T. Takeshita, "Input power factor control of threephase to three-phase matrix converters," IEEJ Transactions on Industry Applications, vol. 129, pp. 258-266, 2009.

[4] M. Venturini and A. Alesina, "The generalised transformer: a new bidirectional, sinusoidal waveform frequency converter with continuously adjustable input power factor," in Power Electronics Specialists Conference, 1980. PESC. IEEE. IEEE, 1980, pp. 242-252.

[5] P. W. Wheeler, J. C. Clare, L. Empringharn, M. Bland, and M. Apap, "Gate drive level intelligence and current sensing for matrix converter current commutation," Industrial Electronics, IEEE Transactions on, vol. 49, no. 2, pp. 382-389, 2002.

[6] D. Casadei, G. Serra, A. Tani, and L. Zarri, "Matrix converter modulation strategies: a new general approach based on space-vector representation of the switch state," Industrial Electronics, IEEE Transactions on, vol. 49, no. 2, pp. 370-381, 2002.

[7] P. Wheeler, J. Clare, L. De Lillo, K. Bradley, M. Aten, C. Whitley, and G. Towers, "A comparison of the reliability of a matrix converter and a controlled rectifier-inverter," in Power Electronics and Applications, 2005 European Conference on. IEEE, 2005, pp. 7-pp.

[8] M. Aten, G. Towers, C. Whitley, P. Wheeler, J. Clare, and K. Bradley, "Reliability comparison of matrix and other converter topologies," Aerospace and Electronic Systems, IEEE Transactions on, vol. 42, no. 3, pp. 867-875, 2006.

[9] L. Empringham, L. De Lillo, S. Khwan-On, C. Brunson, P. Wheeler, and J. Clare, "Enabling technologies for matrix converters in aerospace applications," in Compatibility and Power Electronics (CPE), 2011 7th International Conference-Workshop. IEEE, 2011, pp. 451-456.

[10] R. Peuget, S. Courtine, and J.-P. Rognon, "Fault detection and isolation on a pwm inverter by knowledge-based model," in Industry Applications Conference, 1997. Thirty-Second IAS Annual Meeting, IAS'97., Conference Record of the 1997 IEEE, vol. 2. IEEE, 1997, pp. 1471-1478.

[11] R. L. de Araujo Ribeiro, C. B. Jacobina, E. R. C. Da Silva, and A. M. N. Lima, "Fault-tolerant voltage-fed pwm inverter ac motor drive systems," Industrial Electronics, IEEE Transactions on, vol. 51, no. 2, pp. 439446, 2004.

[12] C. Brunson, L. De Lillo, L. Empringham, P. Wheeler, and J. Clare, "Matrix converter clamp current reconstruction for fault detection," in Power Electronics, Machines and Drives (PEMD 2012), 6th IET International Conference on. IET, 2012, pp. 1-6.

[13] S. Khwan-on, L. de Lillo, L. Empringham, and P. Wheeler, "Opencircuited switch fault detection for fault tolerant matrix converter motor drive systems," in Power Electronics and Applications (EPE 2011), Proceedings of the 2011-14th European Conference on. IEEE, 2011, pp. 1-9. 
[14] C. Brunson, L. Empringham, L. De Lillo, P. Wheeler, and J. Clare, "Open-circuit fault detection and diagnosis in matrix converters," Power Electronics, IEEE Transactions on, vol. 30, no. 5, pp. 2840-2847, 2015. 